\title{
Increased odds of patient-reported success at 2 years after anterior cruciate ligament reconstruction in patients without cartilage lesions: a cohort study from the Swedish National Knee Ligament Register
}

\author{
Eric Hamrin Senorski ${ }^{1} \cdot$ Eduard Alentorn-Geli $^{2,3,4,5} \cdot$ Volker Musahl $^{6} \cdot$ Freddie Fu $^{6}$ • \\ Ferid Krupic $^{7} \cdot$ Neel Desai ${ }^{7,8} \cdot$ Olof Westin $^{7,8} \cdot$ Kristian Samuelsson $^{7,8}$
}

Received: 10 March 2017 / Accepted: 31 May 2017 / Published online: 7 June 2017

(c) The Author(s) 2017. This article is an open access publication

\begin{abstract}
Purpose To investigate whether the surgical technique of single-bundle anterior cruciate ligament (ACL) reconstruction, the visualization of anatomic surgical factors and the presence or absence of concomitant injuries at primary ACL reconstruction are able to predict patient-reported success and failure. The hypothesis of this study was that anatomic single-bundle surgical procedures would be predictive of patient-reported success.

Methods This cohort study was based on data from the Swedish National Knee Ligament Register during the period of 1 January 2005 through 31 December 2014. Patients who underwent primary single-bundle ACL reconstruction with hamstring tendons were included. Details on surgical technique were collected using an online
\end{abstract}

Kristian Samuelsson

kristian@samuelsson.cc

1 Department of Health and Rehabilitation, Institute of Neuroscience and Physiology, The Sahlgrenska Academy, University of Gothenburg, Gothenburg, Sweden

2 Fundación García-Cugat, Barcelona, Spain

3 Artroscopia GC, SL, Barcelona, Spain

4 Mutualidad Catalana de Futbolistas - Delegación Cataluña, Federación Española de Fútbol, Barcelona, Spain

5 Department of Orthopedic Surgery, Mayo Clinic, Rochester, MN, USA

6 Department of Orthopedic Surgery, University of Pittsburgh, Pittsburgh, PA, USA

7 Department of Orthopedics, Institute of Clinical Sciences, The Sahlgrenska Academy, University of Gothenburg, 431 80 Mölndal, Gothenburg, Sweden

8 Department of Orthopedics, Sahlgrenska University Hospital, Mölndal, Sweden questionnaire comprising essential anatomic anterior cruciate ligament reconstruction scoring checklist items, defined as the utilization of accessory medial portal drilling, anatomic tunnel placement, the visualization of insertion sites and pertinent landmarks. A univariate logistic regression model adjusted for age and gender was used to determine predictors of patient-reported success and failure, i.e. 20th and 80th percentile, respectively, in the Knee injury and Osteoarthritis Outcome Score (KOOS), 2 years after ACL reconstruction.

Results In the 6889 included patients, the surgical technique used for single-bundle ACL reconstruction did not predict the predefined patient-reported success or patientreported failure in the $\mathrm{KOOS}_{4}$. Patient-reported success was predicted by the absence of concomitant injury to the meniscus $(\mathrm{OR}=0.81$ [95\% CI, 0.72-0.92], $p=0.001$ ) and articular cartilage $(\mathrm{OR}=0.70$ [95\% CI, 0.61-0.81], $p<0.001)$. Patient-reported failure was predicted by the presence of a concomitant injury to the articular cartilage $(\mathrm{OR}=1.27$ [95\% CI, 1.11-1.44], $p<0.001)$.

Conclusion Surgical techniques used in primary singlebundle ACL reconstruction did not predict the KOOS 2 years after the reconstruction. However, the absence of concomitant injuries at index surgery predicted patientreported success in the KOOS. The results provide further evidence that concomitant injuries at ACL reconstruction affect subjective knee function and a detailed knowledge of the treatment of these concomitant injuries is needed.

Level of evidence Retrospective cohort study, Level III.

Keywords Register - Anterior cruciate ligament $\cdot A C L$. KOOS · Anatomic $\cdot$ Checklist $\cdot$ Patient-reported outcome . Meniscus $\cdot$ Cartilage 


\section{Introduction}

Patient-reported outcome measurements (PROMs) are utilized to highlight the patient's opinion of treatment outcome [23]. For instance, PROMs are commonly used after anterior cruciate ligament (ACL) reconstruction where the Knee injury and Osteoarthritis Outcome Score (KOOS) is one of the most frequently reported ones in the literature $[10,20]$. In the KOOS, it has been suggested that a functional recovery for patients after ACL reconstruction can be defined as the lower threshold for the $95 \%$ CI of healthy 18 - to 34 -year-old males $[2,16]$. Moreover, a treatment failure has been suggested to be a KOOS QoL score of <44 [9].

Previous studies including the KOOS have found that approximately $20-30 \%$ of patients after ACL reconstruction achieve a functional recovery or treatment failure, respectively [2, 9, 12]. One of these studies conducted by Barenius et al. [2] investigated patient-related and surgery-related factors to predict functional recovery and treatment failure in a cohort of patients with ACL reconstruction between 2005 and 2008. With regard to treatment outcome, the authors found that previous surgery on the menisci and a patellar graft were predictors of treatment failure and negative predictors of functional recovery after ACL reconstruction. In addition, a medial meniscus suture or resection at the time of reconstruction was predictive of treatment failure. Since this study was conducted, surgical procedures have evolved, where the use of anatomic reconstruction techniques has increased and has produced improved results in both biomechanical and clinical studies, compared with the older non-anatomic techniques $[13,26]$. To evaluate anatomic ACL reconstructions, a tool, the anatomic anterior cruciate ligament reconstruction scoring checklist (AARSC), has recently been published $[5,25]$. With new opportunities to perform and evaluate ACL reconstructive surgery, it remains to investigate whether detailed knowledge of the surgical procedures, with special emphasis on anatomic reconstruction, is able to predict patient-related outcome after ACL reconstruction.

The purpose of this study was therefore to investigate whether a detailed knowledge of surgical procedures was able to predict which patients have good and poor subjective knee function 2 years after ACL surgery in the Swedish National Knee Ligament Register (SNKLR). Specifically, the aim was to investigate whether the surgical technique of single-bundle ACL reconstruction, the visualization of anatomic surgical factors and the presence or absence of concomitant injuries at primary ACL reconstruction were able to predict patient-reported success and failure. The hypothesis of this study was that anatomic single-bundle surgical procedures would be predictive of patient-reported success. Increased knowledge of which patients do well or worse after treatment may in the future potentially help in terms of selecting appropriate for each individual patient.

\section{Materials and methods}

Patient data were extracted from the SNKLR. Inclusion comprised patients who were registered for primary ACL reconstruction from 1 January 2005 to 31 December 2014. Patients aged 13-49 years who underwent singlebundle ACL reconstruction with hamstring autografts were eligible for inclusion. Follow-up started on the date of the primary ACL reconstruction and ended at the 2-year follow-up, so patients with incomplete data in the KOOS at the 2-year follow-up were excluded. Patients who underwent contralateral ACL or revision ACL surgery before the 2-year follow-up were excluded. Patients were also excluded if the exact dates of index ACL reconstruction or revision surgery or the exact details of the surgeon who performed the surgery were missing. The inclusion and exclusion criteria are summarized in Table 1.

\section{The Swedish National Knee Ligament Register}

The SNKLR is a nationwide database that collects prospective data on ACL injuries and associated knee

Table 1 Summary of inclusion and exclusion criteria

Inclusion criteria
Primary ACL reconstruction
ACL reconstruction using hamstring tendon autograft
Single-bundle ACL reconstruction
Exclusion criteria
Non-primary ACL reconstruction
Non-ACL reconstruction
Year of surgery after 2013
Age other than $13-49$ years
Graft type other than hamstring tendon autograft
Concomitant ligament injury requiring repair/reconstruction
Concomitant fracture/tendon injury
Concomitant vascular injury
Early contralateral ACL or revision surgery, within 550 days of
index surgery
Incomplete data in the KOOS at the 2-year follow-up

$A C L$ anterior cruciate ligament, KOOS Knee injury and Osteoarthritis Outcome Score 
surgery. The register utilizes a web-based protocol consisting of two parts: one surgeon-reported section and one patient-reported section. The surgeon-reported section includes information on the patients' activity at the time of injury, time from injury to reconstruction, graft selection, fixation techniques and previous surgery. The surgeon registers all surgical procedures on the injured knee, including concomitant injuries and treatment of the meniscus and cartilage. The patient-reported section includes two PROMs, the KOOS [20] and European Quality of Life-5 Dimensions (EQ-5D) [17] for healthrelated quality of life. The SNKLR has reported a coverage (proportion of participating units in relation to all eligible units) of $92.9 \%$ and completeness (proportion of target population in the register) of $>90 \%$, with a $50-70 \%$ response rate for the patient-reported outcome measurements [8]. Additionally, a non-response analysis has been done showing that the register is valid despite the suboptimal number of patients responding at follow-up [18]. The register complies with the Swedish legislation relating to data security. All extracted data are anonymous, and investigators only have access to unidentifiable patient data. Participation in the SNKLR is voluntary for patients and surgeons. No written consent is necessary for national registers in Sweden.

\section{Surgical technique of single-bundle ACL reconstruction}

To evaluate the surgical technique, single-bundle ACL reconstruction, an online questionnaire was created to collect detailed information from ACL surgeons in Sweden. The questionnaire included items from the anatomic anterior cruciate ligament reconstruction scoring checklist (AARSC) [5]. The AARSC has been tested for validity and reliability [25]. The questionnaire consists of 17 items covering the surgical technique and one item relating to the documentation of bone tunnel placement. The checklist allows for the calculation of an "anatomic score" with a total of 19 points $[4,5]$. A total of $108(61.7 \%)$ surgeons completed the questionnaire, with a mean nationwide AARSC score based on the questionnaire answers of 13.84 points. The results allowed for a time interval in which the single-bundle surgical techniques that were used could be identified for each surgeon who responded. Accordingly, through the SNKLR, the corresponding patients and surgical techniques could be determined.

\section{Groups}

Groups were created with specific combinations of single-bundle surgical techniques based on eight relevant items selected from the questionnaire. Each group had a mandatory "Yes" or "No" answer requirement for certain items that subsequently identified that particular group (Table 2).

\section{Outcome}

The main outcome and dependent variable was the $\mathrm{KOOS}_{4}$. The KOOS 4 is an average score of four KOOS subscales, in which "function in daily living" is excluded to avoid a ceiling effect [9], because relatively young and active patients, like the patients in this study, rarely have difficulties with function in daily living. We studied the $\mathrm{KOOS}_{4}$ as a predictor in two ways: patient-reported success, defined as $\geq 80$ th percentile, and patient-reported failure, defined as $\leq 20$ th percentile. The definitions were chosen to highlight good and poor subjective outcomes after ACL reconstruction reflected by the top and bottom quantiles in the SNKLR. Surgical techniques of singlebundle ACL reconstruction, surgical factors and concomitant injuries were set as independent variables. The Regional Ethical Review Board in Gothenburg, Sweden, approved this study (D-nr: 760-14).

\section{Statistical analysis}

Tables were generated using Microsoft Word (Version 14.0.7, Microsoft Corp, Redmond, Washington, USA). A statistician assigned to the SNKLR performed all the statistical analyses. Statistical analysis was performed in IBM SPSS Statistics (Version 23.0, IBM Corp, Armonk, New York, USA). Data were characterized according to the level of measurement as nominal scale data and ratio scale data. The means of normally distributed continuous data were compared with the independent-samples $t$ test. Univariate logistic regression was used to predict patientreported success and failure and is reported as an odds ratio $(\mathrm{OR})$ with a $95 \%$ confidence interval. The univariate logistic regression model was adjusted for significant differences in patient baseline characteristics; age and gender. Statistical significance was determined at an alpha level of 0.05 .

\section{Results}

Data from 30,388 unique patients identified in the SNKLR between January 2005 and December 2014. Of these patients, a total of 20,913 were eligible for inclusion and, after applying all the exclusion criteria, 6889 patients were included in the study, 3461 females (50.2\%) and 3428 males (49.8\%) (Fig. 1). Males had a higher subjective knee function measured with the $\mathrm{KOOS}_{4}$ for the age of $7-25$ years $(p<0.001)$ and $31-40$ years $(p<0.01)$. On 


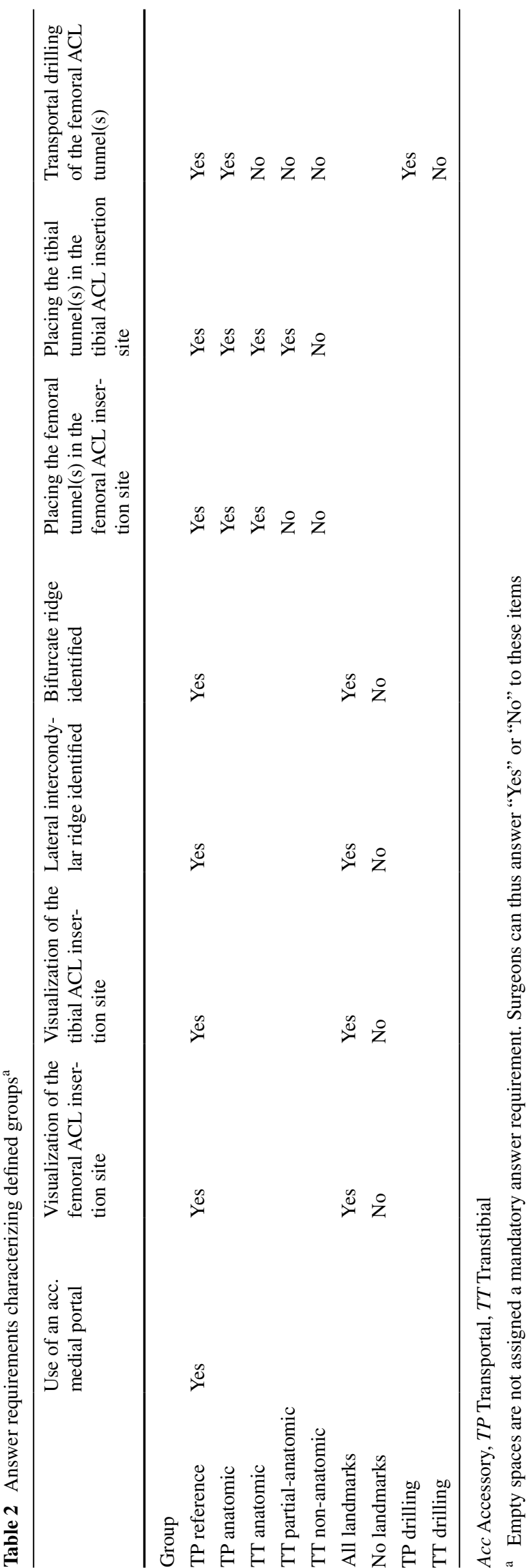

average, the 20th and 80th percentiles of the $\mathrm{KOOS}_{4}$ were higher for males $(p<0.001)$ (Table 3$)$.

\section{Patient-reported success}

Patient baseline characteristics for patient-reported success, i.e. 80th percentile or higher, and the cohort below the 80th percentile in the $\mathrm{KOOS}_{4}$ are presented in Table 4. No differences in the proportion of surgical techniques or surgical procedures were found. The lowest proportion of patients represented in the 80th percentile had undergone ACL reconstruction using the transtibial (TT) partial-anatomic technique. TT partial-anatomic was therefore used as a reference in the logistic regression model.

The absence of a concomitant injury to the menisci was significantly associated with patient-reported success (odds ratio $[\mathrm{OR}]=0.81$ [95\% CI, 0.72-0.92], $p=0.001$ ), as was the absence of cartilage injury $(\mathrm{OR}=0.70$ [0.61-0.81], $p<0.001)$. No associations with surgical techniques or surgical factors were found. However, a subassociation was found in favour of the TT partial-anatomic over the TT anatomic surgical technique $(\mathrm{OR}=1.37$ [95\% CI, 1.07-1.76], $p=0.013)$ (Table 5).

\section{Patient-reported failure}

Patient baseline characteristics for patient-reported failure, i.e. 20th percentile or below, and the cohort above the 20th percentile in the $\mathrm{KOOS}_{4}$ are presented in Table 6. No differences in the proportion of surgical techniques or surgical procedures were found. The lowest proportion of patients represented in the 20th percentile had undergone ACLR using the TT non-anatomic technique. TT non-anatomic was therefore used as a reference in the logistic regression model.

The presence of a concomitant cartilage injury was significantly associated with patient-reported failure $(\mathrm{OR}=1.27$ [95\% CI, 1.11-1.44], $p=0.001)$. No associations with surgical techniques or surgical factors were found. However, a subassociation was found in favour of the TT non-anatomic technique compared with the transportal (TP) reference surgical technique (OR $=1.37$ [95\% CI, 1.07-1.76], $p=0.013$ ) (Table 7).

\section{Discussion}

The main finding was that the absence of concomitant injury to the meniscus and articular cartilage predicted patient-reported success. In addition, the presence of a concomitant injury to cartilage was a predictor of patient-reported failure. Moreover, the surgical 


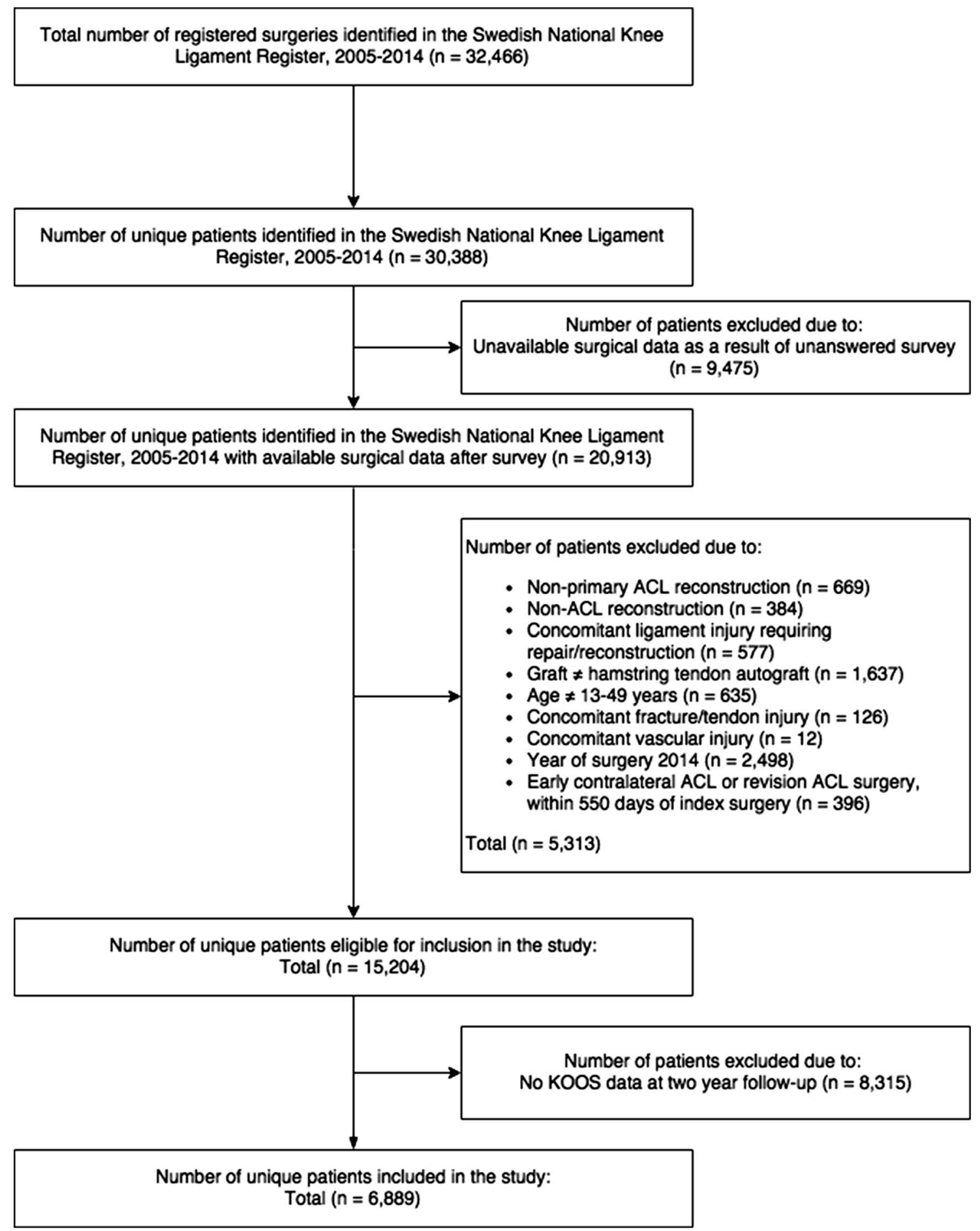

Fig. 1 Flow chart demonstrating the selection of eligible patients from the Swedish National Knee Ligament Register

technique in single-bundle ACL reconstruction did not predict patient-reported success or failure in the $\mathrm{KOOS}_{4}$ at 2 years.

Injuries to the $\mathrm{ACL}$ are common and a reconstruction is one of the most commonly performed outpatient orthopaedic surgeries. Although there is general agreement that it is important to provide axial and rotational stability in the course of surgical reconstruction, the optimal method for doing so remains controversial. It has been suggested that non-anatomically placed grafts are exposed to fewer forces compared with anatomically placed grafts [13]. The non-anatomically placed grafts may also result in residual 


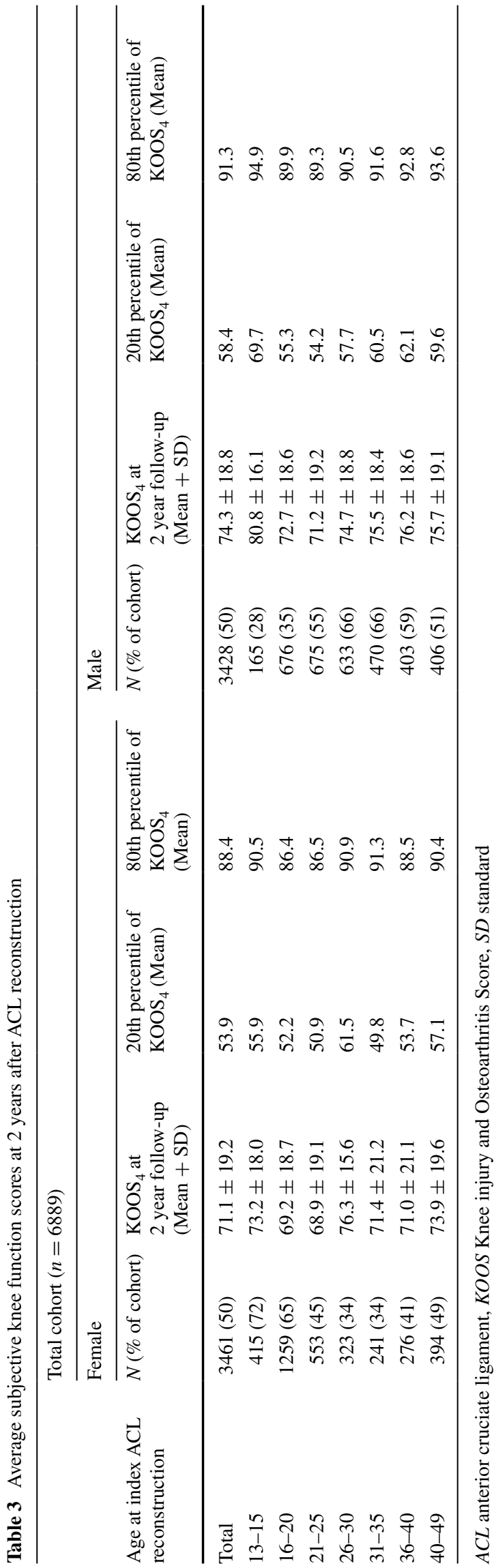

Table 4 Baseline characteristics of patients stratified by patientreported success, i.e. $\geq 80$ th percentile

\begin{tabular}{|c|c|c|c|c|}
\hline & \multicolumn{2}{|c|}{$\begin{array}{l}\text { Success } \geq 80 \text { th } \\
\text { percentile }\end{array}$} & \multicolumn{2}{|c|}{$<80$ th percentile } \\
\hline & $N$ & $\%$ & $N$ & $\%$ \\
\hline \multicolumn{5}{|l|}{$\begin{array}{l}\text { Concomitant injury } \\
(n=1373 \text { vs } 5516)\end{array}$} \\
\hline MCL & 31 & 17.4 & 147 & 82.6 \\
\hline LCL & 10 & 24.4 & 31 & 75.6 \\
\hline Meniscus & 529 & 18.1 & 2400 & 81.9 \\
\hline Cartilage & 297 & 16.0 & 1558 & 84.0 \\
\hline \multicolumn{5}{|l|}{$\begin{array}{l}\text { Surgical techniques } \\
(n=1189 \text { vs } 4797)\end{array}$} \\
\hline $\begin{array}{l}\text { TP reference } \\
(n=2256)\end{array}$ & 442 & 19.6 & 1814 & 80.4 \\
\hline $\begin{array}{l}\text { TT non-anatomic } \\
(n=581)\end{array}$ & 117 & 20.1 & 464 & 79.9 \\
\hline $\begin{array}{l}\text { TT anatomic } \\
(n=944)\end{array}$ & 208 & 22.0 & 736 & 78.0 \\
\hline $\begin{array}{l}\text { TT partial-anatomic } \\
(n=702)\end{array}$ & 120 & 17.1 & 582 & 82.9 \\
\hline $\begin{array}{l}\text { TP anatomic } \\
(n=1503)\end{array}$ & 302 & 20.1 & 1201 & 79.9 \\
\hline \multicolumn{5}{|l|}{ Surgical factors } \\
\hline $\begin{array}{l}\text { Landmarks } \\
(n=3789)\end{array}$ & 76 & 19.4 & 315 & 80.6 \\
\hline $\begin{array}{l}\text { Footprints } \\
(n=5951)\end{array}$ & 106 & 18.0 & 484 & 82.0 \\
\hline $\begin{array}{l}\text { Ridges } \\
(n=5231)\end{array}$ & 285 & 20.8 & 1083 & 79.2 \\
\hline $\begin{array}{l}\text { Drilling TP versus TT } \\
(n=6831)\end{array}$ & 446 & 19.6 & 1832 & 79.9 \\
\hline
\end{tabular}

$M C L$ medial collateral ligament, $L C L$ lateral collateral ligament, $T P$ transportal, $T T$ transtibial

rotational laxity of the knee, creating persisting instability [6]. This instability may cause the patient to adapt his/ her behaviour and activity level, which could potentially affect subjective knee function. Nevertheless, it has been suggested that PROMs provide an indirect measurement of functional stability [24], but the present results may imply that the KOOS is suboptimal and is unable to detect any difference in knee kinematics affected by surgical technique in the short term. Additionally, the KOOS does not include any subscale or question related to perceived instability and the outcome could be too coarse to detect surgery-related differences in the knee. It is also possible to question whether the items in the KOOS are at all relevant when it comes to evaluating surgical outcome after ACL reconstruction. On the other hand, objective measurements of knee stability, such as a quantifiable pivot shift test, may be more appropriate for evaluating surgical technique and identifying small differences in knee-joint kinematics after using different 
Table 5 Logistic regression model for prediction of patient-reported success adjusted for age and gender, i.e. $\geq 80$ th percentile

\begin{tabular}{llll}
\hline Predictor & Odds Ratio & $95 \%$ CI & $p$ value \\
\hline Concomitant injury & & & \\
MCL & 0.84 & $0.57-1.25$ & n.s. \\
LCL & 1.30 & $0.64-2.65$ & n.s. \\
Meniscus & 0.81 & $0.72-0.92$ & 0.001 \\
Cartilage & 0.70 & $0.61-0.81$ & $<0.001$ \\
Surgical techniques & & & n.s. \\
Reference = TT partial-anatomic & & & \\
TP reference & 1.18 & $0.95-1.48$ & n.s. \\
TT non-anatomic & 1.22 & $0.92-1.62$ & n.s. \\
TT anatomic & 1.37 & $1.07-1.76$ & 0.013 \\
TP anatomic & 1.22 & $0.97-1.54$ & n.s. \\
Surgical factors & & & \\
Landmarks & 1.06 & $0.81-1.38$ & n.s. \\
Footprints & 1.17 & $0.94-1.46$ & n.s. \\
Ridges & 0.95 & $0.81-1.10$ & n.s. \\
Drilling (TT vs TP) & 1.04 & $0.91-1.17$ & n.s. \\
\hline
\end{tabular}

Statistical Significance $p<0.05$

$M C L$ medial collateral ligament, $L C L$ lateral collateral ligament, $T T$ transtibial, $C I$ Confidence Interval

ACL reconstruction techniques. However, no data on objective measurements of knee stability are kept at follow-up in the SNKLR.

Single-surgical factors, such as the identification of landmarks, footprints and both ridges, in addition to transtibial or transportal drilling, did not predict patient-reported outcome 2 years after ACL reconstruction in this cohort. Similarly, with regard to single-surgical factors, Duffee et al. [7] compared the transtibial and transportal drilling techniques and reported no association between femoral tunnel drilling and KOOS Sport and KOOS Quality of Life. However, the authors reported that patients who underwent ACL reconstruction where a transtibial technique was used to drill the femoral tunnel had significantly higher odds of undergoing repeat ipsilateral knee surgery compared with those in whom the femoral tunnel had been drilled using an anteromedial portal technique. The authors dichotomized repeat ipsilateral knee surgery after primary ACL reconstruction as "Yes" or "No", including revision ACL surgery, meniscus and cartilage treatment.

In this study, no analysis of concomitant injuries with regard to drilling technique was performed. However, it was shown that an articular cartilage injury at ACL reconstruction significantly affected patient-reported success and failure 2 years after reconstruction. The absence of an articular cartilage injury was a predictor of patient-reported success, but, in comparison, the presence of an articular cartilage injury was a predictor of patient-reported failure. It
Table 6 Baseline characteristics of patients stratified for patientreported failure, i.e. $\leq 20$ th percentile

\begin{tabular}{|c|c|c|c|c|}
\hline & \multicolumn{2}{|c|}{$\begin{array}{l}\text { Failure } \leq 20 \text { th } \\
\text { percentile }\end{array}$} & \multicolumn{2}{|c|}{$\begin{array}{l}>20 \text { th } \\
\text { percentile }\end{array}$} \\
\hline & $N$ & $\%$ & $N$ & $\%$ \\
\hline \multicolumn{5}{|l|}{$\begin{array}{l}\text { Concomitant injury } \\
(n=1373 \text { vs } 5516)\end{array}$} \\
\hline MCL & 38 & 21.3 & 140 & 78.7 \\
\hline LCL & 13 & 31.7 & 28 & 68.3 \\
\hline Meniscus & 610 & 20.8 & 2319 & 79.2 \\
\hline Cartilage & 423 & 22.8 & 1432 & 77.2 \\
\hline \multicolumn{5}{|l|}{$\begin{array}{l}\text { Surgical techniques } \\
(n=1193 \text { vs } 4793)\end{array}$} \\
\hline $\begin{array}{l}\text { TP reference } \\
(n=2256)\end{array}$ & 471 & 20.9 & 1785 & 79.1 \\
\hline $\begin{array}{l}\text { TT non-anatomic } \\
(n=581)\end{array}$ & 99 & 17.0 & 482 & 83.0 \\
\hline $\begin{array}{l}\text { TT anatomic } \\
(n=944)\end{array}$ & 172 & 18.2 & 772 & 81.8 \\
\hline $\begin{array}{l}\text { TT partial-anatomic } \\
(n=702)\end{array}$ & 152 & 21.7 & 550 & 78.3 \\
\hline $\begin{array}{l}\text { TP anatomic } \\
(n=1503)\end{array}$ & 299 & 19.9 & 1204 & 80.1 \\
\hline \multicolumn{5}{|l|}{ Surgical factors } \\
\hline $\begin{array}{l}\text { Landmarks } \\
(n=3789)\end{array}$ & 79 & 20.2 & 312 & 79.8 \\
\hline $\begin{array}{l}\text { Footprints } \\
(n=5951)\end{array}$ & 121 & 20.5 & 469 & 79.5 \\
\hline $\begin{array}{l}\text { Ridges } \\
(n=5231)\end{array}$ & 257 & 18.8 & 1111 & 81.2 \\
\hline Drilling TP versus TT $(n=6831)$ & 440 & 19.3 & 1838 & 79.7 \\
\hline
\end{tabular}

$M C L$ medial collateral ligament, $L C L$ lateral collateral ligament, $T P$ transportal, $T T$ transtibial

is possible to question whether the dichotomization of concomitant injuries, such as articular cartilage injury "Yes" or "No" in our study, may be insufficient when it comes to truly predicting patient-reported outcome after ACL reconstruction. Additionally, the treatment of cartilage or meniscus injury was not controlled for in this study. It might therefore might be possible that these injuries predicted a patient-reported failure only because they were not treated, or adequately treated, and not by the presence of the injury itself. Partly confirming this, Cox et al. [3] showed that grade 3 and 4 articular cartilage lesions in various regions at index ACL reconstruction predicted poorer subjective knee function in the KOOS and International Knee Documentation Committee 6 years after surgery. Nevertheless, a concomitant injury to the articular cartilage appears to have a negative effect on patient-reported outcome [3, $14,21]$. This is a concern in terms of future degenerative changes, osteoarthritis and long-term outcome among these patients $[15,19]$. In the future, it is recommended that the 
Table 7 Logistic regression model for prediction of patient-reported failure adjusted for age and gender, i.e. $\leq 20$ th percentile

\begin{tabular}{llll}
\hline Predictor & Odds ratio & $95 \%$ CI & $p$ value \\
\hline Concomitant injury & & & \\
MCL & 1.09 & $0.76-1.57$ & n.s. \\
LCL & 1.87 & $0.97-3.62$ & n.s. \\
Meniscus & 1.1 & $0.98-1.24$ & n.s. \\
Cartilage & 1.27 & $1.11-1.44$ & $<0.001$ \\
Surgical techniques & & & n.s. \\
Reference = TT non-anatomic & & & \\
TP reference & 1.29 & $1.01-1.63$ & 0.04 \\
TT anatomic & 1.09 & $0.83-1.42$ & n.s. \\
TT partial-anatomic & 1.35 & $1.02-1.78$ & 0.04 \\
TP anatomic & 1.21 & $0.94-1.55$ & n.s. \\
Surgical factors & & & \\
Landmarks & 1.00 & $0.77-1.30$ & n.s. \\
Footprints & 0.98 & $0.79-1.21$ & n.s. \\
Ridges & 1.08 & $0.92-1.26$ & n.s. \\
Drilling (TT vs TP) & 1.06 & $0.94-1.20$ & n.s. \\
\hline
\end{tabular}

Statistical Significance $p<0.05$

$M C L$ medial collateral ligament, $L C L$ lateral collateral ligament, $T T$ transtibial, $T P$ transportal, $C I$ Confidence Interval

emphasis should be placed on treatment strategies aimed at restoring biomechanical function and delaying degenerative changes. Cox et al. [3] also found that medial meniscus injury and treatment at ACL reconstruction negatively affected patient-reported outcome 2 years after surgery. In our cohort, the absence of a meniscus was predictive of patient-reported success, but no effect was found for patient-reported failure. Interestingly, Barenius et al. [2], who investigated functional recovery and treatment failure after ACL reconstruction, found no effect of meniscus injury alone at the time of reconstruction in the KOOS 2 years after surgery. However, in their cohort, also from the SNKLR, a medial meniscus injury that required surgery was a predictor of treatment failure. Taken together, the results appear to provide further evidence of the improved patient-reported outcome in the short term when the meniscus is preserved at ACL reconstruction [2, 3, 21, 22].

The most distinctive potential limitation of this study was the incomplete response to the questionnaire sent out to the surgeons and any recall bias. Nevertheless, the retrospective collection of detailed surgical data was necessary to obtain information relating to items in the AARCS. At present, the data kept in the SNKLR alone are insufficient to evaluate anatomic ACL reconstruction. Assuming correct answers from the questionnaire, the surgeons can still erroneously recall dates at which a certain technique was adopted. To minimize recall bias, responders were asked only to answer the questions if they were sure of the date, by specifying specific years and not months, on which they adopted or abandoned the surgical technique in question. Moreover, all patients who underwent surgery during time periods when the surgeon was "in between" surgical techniques were not included [5]. There were also a large number of patients in the SNKLR with incomplete data and which therefore were excluded from the study. A nonresponse analysis of the SNKLR has been done showing that the register is valid despite the suboptimal number of patients responding at follow-up [18]; however, it cannot be ruled out that the incomplete data may have bias the results. Further limitations of the present study are that rehabilitation and pre-injury sports participation had not been controlled for. A higher pre-injury level of activity has been shown to increase the likelihood of treatment failure after ACL reconstruction [2]. In contrast, elite athletes have a higher rate of return to sport after surgery [1]. In addition, Grindem at el. [11] showed that patients who recover muscle strength and hop performance after ACL reconstruction are substantially less likely to sustain a re-injury to the ACL. Consequently, the incomplete data from muscle function and activity level may be confounders of our results. However, this is the first study to investigate whether anatomic single-bundle ACL reconstruction is able to predict patient-reported outcome 2 years after surgery. This study used the top and bottom quantiles of $\mathrm{KOOS}_{4}$ responses in the SNKLR, defined as patient-reported success and failure. Whether the corresponding $\mathrm{KOOS}_{4}$ for patientreported success and failure correlates to the patients' perception of treatment is not known. Recently, Ingelsrud et al. [12] investigated the proportion of patients who reported acceptable symptoms or treatment failure. Moreover, they also defined the corresponding KOOS values for each subscale of the patients' perception of treatment outcome. The $\mathrm{KOOS}_{4}$ was not investigated, however, with regard to each subscale of the KOOS not including ADL, patients who reported acceptable symptoms had scores between 76 and 91 and patients who reported treatment failure had values between 31 and 58. The range presented for acceptable symptoms and treatment failure is extensive, but it does include the mean $\mathrm{KOOS}_{4}$ values for our cohort and may therefore by comparable. However, the possibility cannot be ruled out that the KOOS could be too coarse to enable the use of predefined percentiles to determine patientreported success and failure.

The strengths of the study include the large sample size in which the data were gathered from the National Knee Ligament Register covering a whole country, which implies that the results are highly generalizable across different hospital settings. The study highlights the fact that, in clinical practice, PROMs such as the KOOS may be insufficient to evaluate the surgical techniques used in single-bundle ACL reconstruction. Additionally, the results provide 
further evidence that concomitant injuries to the articular cartilage and menisci at ACL reconstruction affect subjective knee function and a detailed knowledge of the treatment of these concomitant injuries with respect to the timing of $\mathrm{ACL}$ reconstruction is needed.

\section{Conclusion}

In the present cohort study from the SNKLR, surgical technique was not predictive of patient-reported outcome in the $\mathrm{KOOS}_{4} 2$ years after single-bundle ACL reconstruction. Patient-reported success was predicted by the absence of concomitant injury to the menisci and cartilage. The presence of a concomitant cartilage injury predicted patientreported failure.

Author's contribution EHS, EA-G, FK, and KS have substantial contributed to the acquisition of data, analysis of data, and are responsible of drafting the work and revising it critically for important intellectual content. VM, FF, ND, and OW have done substantial contributions to the conception and design of the work, including interpretation of data. All authors have given their final approval of the manuscript to be published. In addition, all authors are in agreement to be accountable for all aspects of the work in ensuring that questions related to the accuracy or integrity of any part of the work are appropriately investigated and resolved.

\section{Compliance with ethical standards}

Conflict of interest Each author certifies that he or she has no commercial associations (e.g. consultancies, stock ownership, equity interest, patent/licensing arrangements) that might pose a conflict of interest in connection with the submitted article.

Funding No funding was recieved for this study.

Ethical approval This study was approved by the Regional Ethical Review Board in Gothenburg, Sweden, approved this study (D-nr: 760-14).

Informed consent No written consent is necessary for national registries in Sweden.

Open Access This article is distributed under the terms of the Creative Commons Attribution 4.0 International License (http://creativecommons.org/licenses/by/4.0/), which permits unrestricted use, distribution, and reproduction in any medium, provided you give appropriate credit to the original author(s) and the source, provide a link to the Creative Commons license, and indicate if changes were made.

\section{References}

1. Ardern CL, Taylor NF, Feller JA, Webster KE (2014) Fifty-five per cent return to competitive sport following anterior cruciate ligament reconstruction surgery: an updated systematic review and meta-analysis including aspects of physical functioning and contextual factors. Br J Sports Med 48(21):1543-1552

2. Barenius B, Forssblad M, Engstrom B, Eriksson K (2013) Functional recovery after anterior cruciate ligament reconstruction, a study of health-related quality of life based on the Swedish National Knee Ligament Register. Knee Surg Sports Traumatol Arthrosc 21(4):914-927

3. Cox CL, Huston LJ, Dunn WR, Reinke EK, Nwosu SK, Parker RD, Wright RW, Kaeding CC, Marx RG, Amendola A, McCarty EC, Spindler KP (2014) Are articular cartilage lesions and meniscus tears predictive of IKDC, KOOS, and Marx activity level outcomes after anterior cruciate ligament reconstruction? A 6-year multicenter cohort study. Am J Sports Med 42(5):1058-1067

4. Desai N, Alentorn-Geli E, van Eck CF, Musahl V, Fu FH, Karlsson J, Samuelsson K (2016) A systematic review of single- versus double-bundle ACL reconstruction using the anatomic anterior cruciate ligament reconstruction scoring checklist. Knee Surg Sports Traumatol Arthrosc 24(3):862-872

5. Desai N, Andernord D, Sundemo D, Alentorn-Geli E, Musahl V, Fu F, Forssblad M, Samuelsson K (2016) Revision surgery in anterior cruciate ligament reconstruction: a cohort study of 17,682 patients from the Swedish National Knee Ligament Register. Knee Surg Sports Traumatol Arthrosc. doi:10.1007/ s00167-016-4399-0

6. Driscoll MD, Isabell GP Jr, Conditt MA, Ismaily SK, Jupiter DC, Noble PC, Lowe WR (2012) Comparison of 2 femoral tunnel locations in anatomic single-bundle anterior cruciate ligament reconstruction: a biomechanical study. Arthroscopy 28(10): 1481-1489

7. Duffee A, Magnussen RA, Pedroza AD, Flanigan DC, Kaeding CC (2013) Transtibial ACL femoral tunnel preparation increases odds of repeat ipsilateral knee surgery. J Bone Joint Surg Am 95(22):2035-2042

8. Emilsson L, Lindahl B, Koster M, Lambe M, Ludvigsson JF (2015) Review of 103 Swedish healthcare quality registries. J Intern Med 277(1):94-136

9. Frobell RB, Roos EM, Roos HP, Ranstam J, Lohmander LS (2010) A randomized trial of treatment for acute anterior cruciate ligament tears. N Engl J Med 363(4):331-342

10. Granan LP, Forssblad M, Lind M, Engebretsen L (2009) The Scandinavian ACL registries 2004-2007: baseline epidemiology. Acta Orthop 80(5):563-567

11. Grindem H, Snyder-Mackler L, Moksnes H, Engebretsen L, Risberg MA (2016) Simple decision rules can reduce reinjury risk by $84 \%$ after ACL reconstruction: the Delaware-Oslo ACL cohort study. Br J Sports Med 50(13):804-808

12. Ingelsrud LH, Granan LP, Terwee CB, Engebretsen L, Roos EM (2015) Proportion of patients reporting acceptable symptoms or treatment failure and their associated KOOS values at 6 to 24 months after anterior cruciate ligament reconstruction: a study from the Norwegian Knee Ligament Registry. Am J Sports Med 43(8):1902-1907

13. Kato Y, Maeyama A, Lertwanich P, Wang JH, Ingham SJ, Kramer S, Martins CQ, Smolinski P, Fu FH (2013) Biomechanical comparison of different graft positions for singlebundle anterior cruciate ligament reconstruction. Knee Surg Sports Traumatol Arthrosc 21(4):816-823

14. Keays SL, Newcombe PA, Bullock-Saxton JE, Bullock MI, Keays AC (2010) Factors involved in the development of osteoarthritis after anterior cruciate ligament surgery. Am J Sports Med 38(3):455-463

15. Oiestad BE, Holm I, Aune AK, Gunderson R, Myklebust G, Engebretsen L, Fosdahl MA, Risberg MA (2010) Knee function and prevalence of knee osteoarthritis after anterior 
cruciate ligament reconstruction: a prospective study with 10 to 15 years of follow-up. Am J Sports Med 38(11):2201-2210

16. Paradowski PT, Bergman S, Sunden-Lundius A, Lohmander LS, Roos EM (2006) Knee complaints vary with age and gender in the adult population. Population-based reference data for the Knee injury and Osteoarthritis Outcome Score (KOOS). BMC Musculoskelet Disord 7:38

17. Rabin R, de Charro F (2001) EQ-5D: a measure of health status from the EuroQol Group. Ann Med 33(5):337-343

18. Reinholdsson J, Kraus-Schmitz J, Forssblad M, Edman G, Byttner M, Stalman A (2016) A non-response analysis of 2-year data in the Swedish Knee Ligament Register. Knee Surg Sports Traumatol Arthrosc. doi:10.1007/s00167-015-3969-x

19. Risberg MA, Oiestad BE, Gunderson R, Aune AK, Engebretsen L, Culvenor A, Holm I (2016) Changes in knee osteoarthritis, symptoms, and function after anterior cruciate ligament reconstruction: a 20-year prospective follow-up study. Am J Sports Med 44(5):1215-1224

20. Roos EM, Roos HP, Lohmander LS, Ekdahl C, Beynnon BD (1998) Knee Injury and Osteoarthritis Outcome Score (KOOS)development of a self-administered outcome measure. J Orthop Sports Phys Ther 28(2):88-96

21. Rotterud JH, Sivertsen EA, Forssblad M, Engebretsen L, Aroen A (2013) Effect of meniscal and focal cartilage lesions on patient-reported outcome after anterior cruciate ligament reconstruction: a nationwide cohort study from Norway and Sweden of 8476 patients with 2-year follow-up. Am J Sports Med 41(3):535-543

22. Seil R, Becker R (2016) Time for a paradigm change in meniscal repair: save the meniscus! Knee Surg Sports Traumatol Arthrosc 24(5):1421-1423

23. Speight J, Barendse SM (2010) FDA guidance on patient reported outcomes. BMJ 340:c2921

24. Thorstensson CA, Lohmander LS, Frobell RB, Roos EM, Gooberman-Hill R (2009) Choosing surgery: patients' preferences within a trial of treatments for anterior cruciate ligament injury. A qualitative study. BMC Musculoskelet Disord 10:100

25. van Eck CF, Gravare-Silbernagel K, Samuelsson K, Musahl V, van Dijk CN, Karlsson J, Irrgang JJ, Fu FH (2013) Evidence to support the interpretation and use of the anatomic anterior cruciate ligament reconstruction checklist. J Bone Joint Surg Am 95(20): 153

26. Yamamoto Y, Hsu WH, Woo SL, Van Scyoc AH, Takakura Y, Debski RE (2004) Knee stability and graft function after anterior cruciate ligament reconstruction: a comparison of a lateral and an anatomical femoral tunnel placement. Am J Sports Med 32(8):1825-1832 